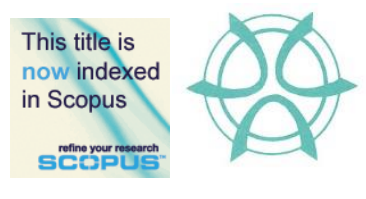

PLANNING MALAYSIA:

Journal of the Malaysian Institute of Planners

VOLUME 16 ISSUE 2 (2018), Page 314 - 323

\title{
PHYSICOCHEMICAL PROPERTIES AND POZZOLANIC PERFORMANCE OF ULTRAFINE TREATED RICE HUSK ASH (UFTRHA) AS ADDITIVE IN CONCRETE
}

\author{
Siti Asmahani Saad ${ }^{1}$, Nasir Shafiq ${ }^{2} \&$ Maisarah Ali $^{3}$ \\ ${ }^{1,3}$ Kulliyyah of Engineering, \\ INTERNATIONAL ISLAMIC UNIVERSITY MALAYSIA \\ ${ }^{2}$ Faculty of Engineering, \\ UNIVERSITI TEKNOLOGI PETRONAS, MALAYSIA
}

\begin{abstract}
Rice husk ash (RHA) contains high amount of amorphous silica that is ubiquitous in the pozzolanic reaction of SCM in concrete. However, usage of conventional RHA is currently unfavourable in concrete industry due to its properties inconsistency. In this regard, improvement on the RHA properties by introduction of thermochemical pre-treatment prior to burning procedure is seen as an excellent way to reach the goal. In this paper, raw rice husk was pre-treated using $0.1 \mathrm{~N}$ hydrochloric acid $(\mathrm{HCl})$ and heated at $80^{\circ} \mathrm{C}$. It was then mechanically activated by high energy planetary ball mill for 15 minutes at speed of 300rpm and ball-to-powder ratio (BPR) of 15:1. The chemical composition, mineralogical properties, particle size analysis, specific surface area as well as microstructure properties of ultrafine treated rice husk ash (UFTRHA) were determined accordingly. As for amorphous silica content of the optimum sample was recorded as $98.60 \%$ incinerated at $600^{\circ} \mathrm{C}$ with four hours of pre-treatment soaking duration. In terms of particle size and specific surface, it was also observed that, burning temperature of $600^{\circ} \mathrm{C}$, pre-treated at four hours were recorded to produce finest size of UFTRHA where $\mathrm{d}(0.1), \mathrm{d}(0.5)$ and $\mathrm{d}(0.9)$ were obtained as 1.416 $\mu \mathrm{m}, 4.364 \mu \mathrm{m}$ and $14.043 \mu \mathrm{m}$ respectively. Largest specific surface area value was obtained at $219.58 \mathrm{~m}^{2} / \mathrm{g}$ with the similar pre-treatment conditions. Meanwhile, the strength activity of UFTRHA from the optimum pre-treatment process was measured by testing the compressive strength of mortars. The highest compression value obtained was $50.17 \mathrm{MPa}$ with $3 \%$ UFTRHA replacement at 28 days.
\end{abstract}

Keyword: Ultrafine Treated Rice Husk Ash (UFTRHA), concrete additive material, rice husk ash, physicochemical, high energy grinding 
Siti Asmahani Saad, Nasir Shafiq \& Maisarah Ali

Physicochemical Properties and Pozzolanic Performance of Ultrafine Treated Rice Husk Ash (UFTRHA) as Additive in

Concrete

\section{INTRODUCTION}

In current research trend, most researchers have promoted green technology application widely. This phenomenon encourages recent explorations of the application of additive materials in concrete industry. Additive materials are commonly used in concrete as admixtures to enhance its properties and also to promote greener concrete production. Rice husk ash (RHA) is regarded as one of concrete additive materials due to its high silica content. Production of RHA is done via thermal activation, which involves burning process of the rice husk from agricultural waste.

Rice plant is a type of plant that has the ability to absorb silica content from soil. The absorbed silica eventually assimilates into the plant structure during its growth. Therefore, the outer part, which is the rice husk, possesses high silica content with value of more than $80 \%$ (Juenger \& Siddique, 2015) Approximately 1,000 million tons of rice are annually produced in the world, which usually leaves about 400 million tons of rice husks as waste material (Food Agriculture Organization (FAO), 2015). Hence, the potential of producing ash from husk is about 100 million tons per annum. Therefore, utilizing RHA in concrete is possible. Furthermore, high content of amorphous silica and high specific surface area (SSA) of RHA are possible to be achieved by adopting suitable burning condition (Mehta \& Monteiro, 2006). Thus, incorporation of RHA in concrete production promotes environmental as well as economic relief. Compared to other additive types such as silica fume (SF) and fly ash (FA), RHA is proven to have greater reaction with portlandite $(\mathrm{Ca}(\mathrm{OH}) 2)$ in pozzolanic reaction, contributes towards increment in compressive strength value and durability of high performance concrete (Feng, Yamamichi, Shoya, \& Sugita, 2004; Salas, Delvasto, de Gutierrez, \& Lange, 2009; Van, Rößler, Bui, \& Ludwig, 2013) and ultra-high performance concrete as well (Van, Rößler, Bui, \& Ludwig, 2014a; . Van, Rößler, Bui, \& Ludwig, 2014b; Van Tuan, Ye, Van Breugel, \& Copuroglu, 2011; Van Tuan, Ye, Van Breugel, Fraaij, \& Bui, 2011).

In order to ascertain high amount of amorphous silica content from rice husk, metal impurities i.e. potassium and magnesium that encapsulate the rice husk surface should be removed. Elimination of these metal impurities is possible through thermochemical pre-treatment process using inorganic acid i.e. hydrochloric acid $(\mathrm{HCl})$ and nitric acid (HNO3) (Park, Salas, Chung, \& Lee, 2014; Salas et al., 2009; Vayghan, Khaloo, \& Rajabipour, 2013). The thermochemical pre-treatment process is able to reduce the sensitivity of RHA towards burning temperature (Feng et al., 2004). Therefore, in this paper, the main focus is to examine the optimum physicochemical attributes of treated RHA produced precisely. 


\section{METHODOLOGY}

\section{Ultrafine Treated Rice Husk Ash (UFTRHA) Pre-treatment Process Flow}

Raw rice husk was obtained from local rice factory (BERNAS) located in Sungai Ranggam, Perak. Prior to incineration procedure, the rice husk was treated with $0.1 \mathrm{~N}$ analytical grade (A.G.) hydrochloric acid $(\mathrm{HCl})$. The specimens were soaked and heated at $80^{\circ} \mathrm{C}$ in the acid solution. After completion of pre-treatment process, the samples were washed using distilled water until its neutral $\mathrm{pH}$ obtained and dried using laboratory oven at $110^{\circ} \mathrm{C}$. It was then burned by using conventional furnace in laboratory. The burning process was done at $600^{\circ} \mathrm{C}, 700^{\circ} \mathrm{C}$ and $800^{\circ} \mathrm{C}$ with 1 hour retention time. The ultrafine treated rice husk ash (UFTRHA) was then ground using planetary ball mill for 15 minutes with ballto-powder ratio (BPR) of 15:1 and rotation speed at 300rpm.

\section{Physicochemical Characteristic of (UFTRHA)}

In this study, chemical composition of UFTRHA prepared at various burning temperatures was examined using X-ray fluorescence (XRF) test. The test was done for UFTRHA sample that undergone pre-treatment in $0.1 \mathrm{~N} \mathrm{HCl}$ solution at $80^{\circ} \mathrm{C}$. The analysis was done by using spectrometer of Bruker Axs S4 Pioneer. The test was in compliance with BS EN 12677. As for mineralogical properties determination, X-Ray diffraction (XRD) analysis was done accordingly. This test was conducted using Bruker Axs D8 Advance X-Ray Diffractometer instrument.

Brunnet emmet teller (BET) nitrogen adsorption test was done to examine particle specific surface area of the ground UFTRHA powder. The test was completed with degassing temperature of $300^{\circ} \mathrm{C}$ using surface area and pore analyser model micromeritics ASAP 2020. Meanwhile, particle size analysis (PSA) was done using Malvern instrument mastersizer, model Scirocco 2000.

\section{Pozzolanic / Strength Activity Index}

In order to ensure that the UFTRHA is a reactive pozzolan, it is vital to conduct strength activity index test. Thus, this test was completed in accordance to ASTM C311-98b specifically for ordinary Portland cement (OPC) mortar (ASTM, 2016). The mortars were prepared by blending OPC with the highest $\mathrm{SiO}_{2}$ content of UFTRHA at $20 \%$ replacement level. The strength activity index was calculated as the following equation:

Strength Activity Index $(\mathrm{SAI})=(\mathrm{B} / \mathrm{A}) \times 100$

*Where B is the compressive strength value of blended cement at $20 \%$ replacement level; A is the compressive strength of control mix 
Siti Asmahani Saad, Nasir Shafiq \& Maisarah Ali

Physicochemical Properties and Pozzolanic Performance of Ultrafine Treated Rice Husk Ash (UFTRHA) as Additive in

Concrete

\section{RESULTS AND DISCUSSION}

\section{Chemical Composition of UFTRHA}

Based on the experimental result, it can be observed that the predominant content of rice husk ash is silica $\left(\mathrm{SiO}_{2}\right)$. In addition, the $\mathrm{SiO}_{2}$ composition in UFTRHA incinerated at $600^{\circ} \mathrm{C}$ has highest value among other samples that were prepared at $700^{\circ} \mathrm{C}$ and $800^{\circ} \mathrm{C}$. According to the XRF analysis result, the $\mathrm{SiO}_{2}$ content in UFTRHA sample produced at $600^{\circ} \mathrm{C}$ increased with percentage values of $1.62 \%$ and $8.82 \%$ as compared to the samples extracted at $700^{\circ} \mathrm{C}$ and $800^{\circ} \mathrm{C}$ respectively. This finding also indicate that the ideal burning temperature to produce UFTRHA is $600^{\circ} \mathrm{C}$. The chemical composition determination of UFTRHA, X-Ray Fluorescence (XRF) data is summarized in Table 1.

In addition, the amount of alkali metal oxides i.e. sodium oxide $\left(\mathrm{Na}_{2} \mathrm{O}\right)$, magnesium oxide $(\mathrm{MgO})$, calcium oxide $(\mathrm{CaO})$ and potassium oxide $\left(\mathrm{K}_{2} \mathrm{O}\right)$ contents at all three different burning temperatures were obtained less than $1 \%$. Less in amount of these metallic impurities is vital to enhance the purity of silica extracted from rice husk. By lowering the content of these metallic oxides, especially potassium and sodium, surface melting of $\mathrm{SiO}_{2}$ particles can be reduced effectively. The surface melting of $\mathrm{SiO}_{2}$ phenomenon will accelerate early crystallization of amorphous $\mathrm{SiO}_{2}$ into cristobalite as suggested by several researches in this area (James \& Subbarao, 1986; Kalapathy, Proctor, \& Shultz, 2001; Krisnarao \& Godkhindi, 1992; Real, Alcala, \& Criado, 1996).

Table 1: Chemical composition of UFTRHA treated for 4 hours at various burning temperature

\begin{tabular}{cccc}
\hline $\begin{array}{c}\text { Chemical } \\
\text { composition }\end{array}$ & \multicolumn{3}{c}{$\begin{array}{c}\text { Chemical content of UFTRHA using 0.1N HCl with soaking } \\
\text { duration at } 4 \text { hours }(\%)\end{array}$} \\
\hline $\mathrm{CC}$ & $600^{\circ} \mathrm{C}$ & $700^{\circ} \mathrm{C}$ & $800^{\circ} \mathrm{C}$ \\
$\mathrm{SiO}_{2}$ & 98.60 & 97.00 & 89.90 \\
$\mathrm{P}_{2} \mathrm{O}_{5}$ & 0.53 & 1.63 & 1.48 \\
$\mathrm{Fe}_{2} \mathrm{O}_{3}$ & 0.06 & 0.25 & 6.62 \\
$\mathrm{CaO}$ & 0.36 & 0.46 & 0.48 \\
$\mathrm{Al} \mathrm{O}_{3}$ & 0.13 & 0.09 & - \\
$\mathrm{K} 2 \mathrm{O}$ & 0.06 & 0.11 & - \\
$\mathrm{Na} 2 \mathrm{O}$ & - & - & - \\
$\mathrm{MgO}$ & - & - & 0.89 \\
$\mathrm{MnO}$ & - & - & 0.24 \\
$\mathrm{SO}_{3}$ & - & - & - \\
$\mathrm{Cl}$ & - & - & - \\
$\mathrm{ZrO}_{3}$ & 0.22 & 0.25 & 0.12 \\
\hline
\end{tabular}

\section{Minerological Characteristics of UFTRHA}

Amorphousness and crystallinity degree of a material can be determined using the X-Ray diffraction analysis. This analysis was also utilized to determine 
mineral presence in the tested material. Figure 1 illustrates the XRD patterns of UFTRHA incinerated at $600^{\circ} \mathrm{C}, 700^{\circ} \mathrm{C}$ and $800^{\circ} \mathrm{C}$ respectively.

Based on the XRD analysis, it was noted that all samples of UFTRHA prepared at all temperatures variation i.e. $600^{\circ} \mathrm{C}, 700^{\circ} \mathrm{C}$ and $800^{\circ} \mathrm{C}$ were amorphous and without the presence of high intensity peaks. Hence, it is proven that sensitivity towards burning temperature has been eliminated by removing impurities on the surface of the raw rice husk via the pre-treatment process prior to incineration stage. Amorphous state of silica content is vital in order to produce high quality additive material in concrete industry application.

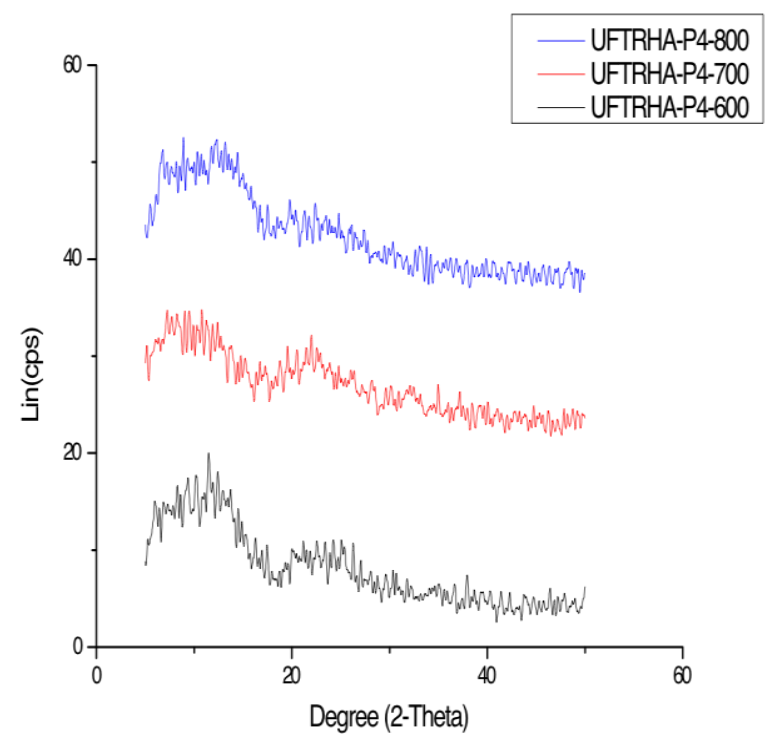

Figure 1: XRD patterns of UFTRHA incinerated at $600^{\circ} \mathrm{C}, 700^{\circ} \mathrm{C}$ and $800^{\circ} \mathrm{C}$ respectively

\section{Physical Properties of UFTRHA}

Among many of the feasible methods to be used for material size reduction is the mechanical milling process. Hence, this method was adopted in order to reduce size of UFTRHA powder particle. This milling mechanism is attainable using planetary ball mill (Saad, Nuruddin, Shafiq, \& Ali, 2016). In this regard, several parameters of the mechanical milling process are to be considered namely milling speed, ball-to-powder ratio (BPR) and duration of grinding.

Table 2 tabulates the particle size analysis of UFTRHA at 4 hours pretreatment duration and various burning temperature with milling speed, BPR and grinding duration of 300rpm, 15:1 and 15 minutes respectively. 
Siti Asmahani Saad, Nasir Shafiq \& Maisarah Ali

Physicochemical Properties and Pozzolanic Performance of Ultrafine Treated Rice Husk Ash (UFTRHA) as Additive in

Concrete

Table 2: Particle size analysis of UFTRHA at various burning temperature at 4 hours of soaking time.

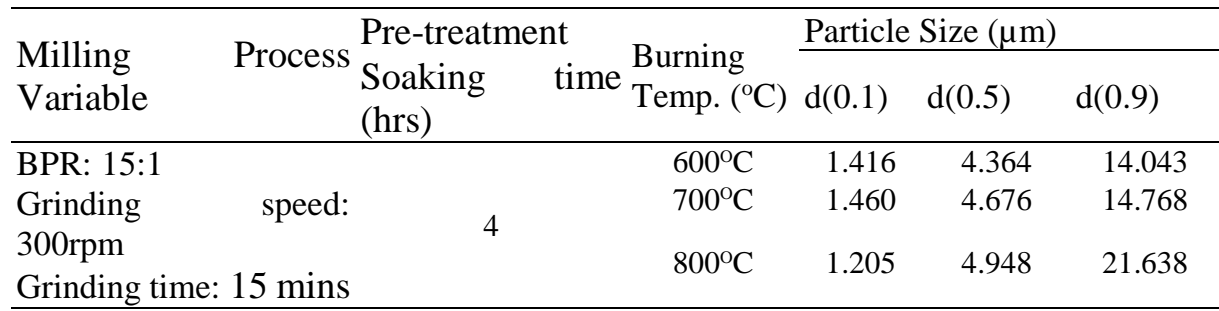

High speed of the grinding process resulted in greater velocity of the ball movements in the milling bowl. Therefore, shearing impact between grinding media (balls) and feed stock (UFTRHA) occurs vigorously in the system hence the smaller particle size obtained (Saad et al., 2016). Based on the data in Table 3 , UFTRHA that had been treated for four hours and incinerated at $600^{\circ} \mathrm{C}$ has finest particle size compared to other UFTRHA samples with $\mathrm{d}(0.1), \mathrm{d}(0.5)$ and $\mathrm{d}(0.9)$ of $1.416 \mu \mathrm{m}, 4.364 \mu \mathrm{m}$ and $14.043 \mu \mathrm{m}$ respectively.

On the other hand, Table 3 shows the influence of different burning temperature towards specific surface area (SSA) value of UFTRHA pre-treated using $0.1 \mathrm{~N} \mathrm{HCl}$ for four hours as well. Specific surface area (SSA) value plays an important role in accelerating the pozzolanic reaction of additive materials. Furthermore, large surface area of the pozzolanic material particle also acts as seeds for the generation of denser calcium-silicate-hydrate phase $(\mathrm{C}-\mathrm{S}-\mathrm{H})$ in enhancing concrete strength development. From the SSA analysis, the highest specific surface area of UFTRHA sample was obtained as $219.58 \mathrm{~m}^{2} / \mathrm{g}$. This finding is in agreement with the previous experimental analysis where the highest $\mathrm{SiO}_{2}$ content and finest median particle size were obtained from UFTRHA that was burned at $600^{\circ} \mathrm{C}$ with four hours of acid pre-treatment procedure. According to data in Table 3, the SSA values reduced as the burning temperature rose up to $800^{\circ} \mathrm{C}$.

Table 3: Response of Brunnet Emmet Teller - Specific Surface Area (BET-SSA) values to different burning temperatures of UFTRHA pre-treated at 4 hours

\begin{tabular}{llll}
\hline \multirow{2}{*}{$\begin{array}{l}\text { BET-SSA Value for Different } \\
\text { Sample Type }\left(\mathrm{m}^{2} / \mathrm{g}\right)\end{array}$} & \multicolumn{3}{l}{ Burning Temperature $\left({ }^{\circ} \mathrm{C}\right)$} \\
\cline { 2 - 4 } & $600{ }^{\circ} \mathrm{C}$ & $700{ }^{\circ} \mathrm{C}$ & $800{ }^{\circ} \mathrm{C}$ \\
\hline UFTRHA (acid pre-treated) & 219.58 & 180.72 & 133.91 \\
\hline
\end{tabular}

\section{Pozzolanic / Strength Activity Index Analysis}

For further examination of pozzolanic level of UFTRHA as additive material in concrete, strength activity index (SAI) test was done accordingly. The mix 
proportion of SAI test is tabulated in Table 4, where compression values of $50 \mathrm{~mm}^{3}$ cube samples with $20 \%$ of UFTRHA replacement were determined at 7 and 28 days respectively.

From the analysis, the SAI values of UFTRHA blended mortar were recorded as $137.17 \%$ and $148.21 \%$ at 7 and 28 days respectively. These findings give an indication that UFTRHA possesses an excellent pozzolanic / cementing properties, where minimum requirement of strength activity index (SAI) of 75\% at both 7 and 28 days as per outlined in ASTM C618-00 (ASTM, 2015).

Table 4: Mix proportions for strength activity index (SAI) analysis

\begin{tabular}{ccc}
\hline Constituent & Control Mix (A) & UFTRHA Blended Mix (B) \\
\hline OPC $(\mathrm{g})$ & 450 & 360 \\
Sand $(\mathrm{g})$ & 1350 & 1350 \\
UFTRHA $(\mathrm{g})$ & - & 90 \\
Water $(\mathrm{g})$ & 225 & 225 \\
\hline
\end{tabular}

\section{CONCLUSION}

The results obtained shows that, the optimum conditions in pre-treatment process play important roles in terms of enhancing the physicochemical properties of UFTRHA. These properties are important in order to produce high quality additive material for concrete technology application. As for the chemical composition analysis, the highest purity of silica content $\left(\mathrm{SiO}_{2}\right)$ is achieved by incineration at $600^{\circ} \mathrm{C}$ of four hours pre-treated rice husk. On the other hand, the mineralogical assessment concluded that the silica is amorphous as no significant sharp peak presence in XRD analysis at all burning temperatures. The highest amorphous silica content $\left(\mathrm{SiO}_{2}\right)$ of the UFTRHA sample was recorded at $98.60 \%$ with particle size median of $4.364 \mu \mathrm{m}$ and specific surface area of $219.58 \mathrm{~m}^{2} / \mathrm{g}$. Meanwhile, the strength activity index of UFTRHA than that of the control mortar at 7 and 28 days were calculated as $137.17 \%$ and $148.21 \%$ subsequently.

\section{ACKNOWLEDGEMENT}

The author would like express profound gratitude to the Ministry of Education of Malaysia (MoE) for funding the research work under MyRa Grant Scheme.

\section{REFERENCES}

ASTM. (2015). ASTM C618-15 standard specification for coal fly ash and raw or calcined natural pozzolan for use in concrete. doi.org/10.1520/C0618-15

ASTM. (2016). C311/C311m-16 standard test methods for sampling and testing fly ash or natural pozzolans for use. doi.org/10.1520/C0311-11a.2

Feng, Q., Yamamichi, H., Shoya, M., \& Sugita, S. (2004). Study on the pozzolanic properties of rice husk ash by hydrochloric acid pretreatment. Cement and Concrete Research, 34(3), 521-526.

Food Agriculture Organization [FAO]. (2015). Rice market monitor April 2015 (Vol. 18) James, J., \& Subbarao, M. (1986). Characterization of silica in rice husk ash. American 
Siti Asmahani Saad, Nasir Shafiq \& Maisarah Ali

Physicochemical Properties and Pozzolanic Performance of Ultrafine Treated Rice Husk Ash (UFTRHA) as Additive in

Concrete

Ceramic Society Bulletin, 65(8), 1177-1180.

Juenger, M. C. G., \& Siddique, R. (2015). Recent advances in understanding the role of supplementary cementitious materials in concrete. Cement and Concrete Research, 78, 71-80.

Kalapathy, U., Proctor, A., \& Shultz, J. (2001). A simple method for production of pure silica from rice hull ash. Fuel and Energy Abstracts, 42(1), 45.

Krisnarao, R. V., \& Godkhindi, M. M. (1992). Studies on the Formation of SiC Whikers from Pulverized Rice Husk Ashes. Ceramics International, 18, 35-42.

Mehta, P. K., \& Monteiro, P. J. M. (2006). Concrete: microstructure, properties, and materials. McGraw-Hill Education.

Park, C., Salas, A., Chung, C.-W., \& Lee, C. J. (2014). Freeze-thaw resistance of concrete using acid-leached rice husk ash. KSCE Journal of Civil Engineering, 18(4), 1133-1139.

Real, C., Alcala, M. D., \& Criado, J. M. (1996). Preparation of silica from rice husks. Journal of the American Ceramic Society, 79(8), 2012-2016.

Saad, S. A., Nuruddin, M. F., Shafiq, N., \& Ali, M. (2016). The effect of incineration temperature to the chemical and physical properties of Ultrafine Treated Rice Husk Ash (UFTRHA) as Supplementary Cementing Material (SCM). Procedia Engineering, 148, 163-167.

Salas, A., Delvasto, S., de Gutierrez, R. M., \& Lange, D. (2009). Comparison of two processes for treating rice husk ash for use in high performance concrete. Cement and Concrete Research, 39(9), 773-778.

Van, V. T. A., Rößler, C., Bui, D., \& Ludwig, H. (2014a). Cement \& Concrete Composites Rice husk ash as both pozzolanic admixture and internal curing agent in ultra-high performance concrete. Cement and Concrete Composites, 53, 270-278

Van, V. T. A., Rößler, C., Bui, D. D., \& Ludwig, H. M. (2014b). Pozzolanic reactivity of mesoporous amorphous rice husk ash in portlandite solution. Construction and Building Materials, 59, 111-119.

Van, V. T. A., Rößler, C., Bui, D. D., \& Ludwig, H. M. (2013). Mesoporous structure and pozzolanic reactivity of rice husk ash in cementitious system. Construction and Building Materials, 43, 208-216.

Van Tuan, N., Ye, G., Van Breugel, K., \& Copuroglu, O. (2011). Hydration and microstructure of ultra high performance concrete incorporating rice husk ash. Cement and Concrete Research, 41(11), 1104-1111.

Van Tuan, N., Ye, G., Van Breugel, K., Fraaij, A. L. A., \& Bui, D. D. (2011). The study of using rice husk ash to produce ultra high performance concrete. Construction and Building Materials, 25(4), 2030-2035.

Vayghan, A. G., Khaloo, A. R., \& Rajabipour, F. (2013). The effects of a hydrochloric acid pre-treatment on the physicochemical properties and pozzolanic performance of rice husk ash. Cement and Concrete Composites, 39, 131-140. 